\title{
Knowledge Management System Untuk SDM Menggunakan Seci Model (Studi Kasus: Koperasi Karyawan)
}

\author{
Eva Zuraidah \\ STMIK Nusa Mandiri \\ e-mail: Zuraidahevasiti@yahoo.co.id
}

\begin{abstract}
Abstrak
Koperasi Pegawai Badan Urusan Logistik adalah sebuah Koperasi yang bergerak dalam bidang jasa, simpan-pinjam. Knowledge Managment System tersebut, nampaknya sudah menjadi suatu kebutuhan mendasarkan untuk meningkatkan kualitas sumber daya manusia yang khususnya kepada karyawan. Knowledge management merupakan usaha untuk meningkatkan knowledge yang berguna dalam koperasi. Knowledge management tidak hanya merupakan pengaturan akan knowldge, namun lebih pada manajemen suatu koperasi dengan fokus khususnya terhadap knowledge, knowledge management dengan sebuah sistem, yang diharapkan dapat menjadi solusi dari kebutuhan aliran knowledge yang tidak dihalangi oleh batasan waktu dan tempat. Penelitian ini akan mengembangkan analisa knowledge management system dan merancang aplikasi dari analisa yang dikembangkan. Metodologi yang digunakan dengan model SECl dan melakukan analisa untuk mendapatkan knowledge management system tersebut. Analisa knowledge management system yang dihasilkan mendukung proses Sosialisasi, Eksternalisasi, Kombinasi, Internalisasi (SECI). Knowledge management system ini dikembangkan sebagai sarana sharing pada karyawan.
\end{abstract}

Kata kunci: Knowledge Management System,SECI, Koperasi,SDM

\begin{abstract}
Employee Cooperative Agency of Logistics Affairs is a cooperative engaged in services, savings, and loans. Knowledge Managment System, it seems to have become a basic need to improve the quality of human resources, especially to employees. Knowledge management is an attempt to improve knowledge useful in cooperatives. Knowledge management is not only an arrangement of knowledge but rather the management of a cooperative with a particular focus on knowledge, knowledge management with a system, which is expected to be a solution of the needs of the flow of knowledge that is not hindered by time and space constraints. This research will develop the knowledge management system and design the application of the developed analysis. The methodology used with the SECI model and perform the analysis to obtain the knowledge management system. The analysis of the resulting knowledge management system supports the process of Socialization, Externalization, Combination, Internalization (SECI). Knowledge management system was developed as a means of sharing in employees
\end{abstract}

Keywords: Knowledge Management System, SECI, Koperasi, SDM

\section{Pendahuluan}

Perkembangan ilmu pengetahuan dalam era globalisasi terjadi dengan sangat cepat. Kemampuan manusia dalam mengembangkan berbagai ilmu pengetahuan (knowledge) semakin baik dengan adanya knowledge secara tacit dan explicit.Tacit knowledge adalah pengetahuan yang terdapat dalam pikiran tiap manusia secara personal. Explicit knowledge adalah pengetahuan disimpan atau ditulis dalam suatu media. Dari pengembangan tersebut maka pengetahuan secara tacit dan explicit dapat digabungkan dan divariasikan hingga menjadi Knowledge Management System Menurut Tiwana (2000) pengetahuan akan semakin berharga bila bersifat context-specific atau tacit knowledge yang tertanam dalam dinamika organisasi yang kompleks dan dikembangkan melalui pengalaman. 
Misalnya pengetahuan yang terakumulasi akibat pengalaman mengelola sistem informasi koperasi atau keuangan merupakan pengetahuan terbatinkan yang sulit dipelajari atau diperoleh tanpa melalui pengalaman yang sama, walau pun pengetahuan tersebut dapat dituangkan dalam bentuk manual atau standar operasional prosedur (SOP).

Kesadaran untuk menerapkan pendekatan Knowledge Management ke dalam strategi bisnis diperlukan karena terbuktinya perusahaan yang menjadikan knowledge sebagai asset utamnya senantiasa mendorong perusahaan lebih inovatif yang bermuara .

Selama ini pengolaan knowledge dalam koperasi ini masih tidak terdistribusi dengan baik. Sifatnya masih individu ke individu, secara lisan dan tidak terdokumentasi. Knowledge seorang karyawan yang sudah keluar dari koperasi tidak diwariskan kepada penggantinya. Sebaliknya karyawan baru masuk kekoperasi tidak terwariskan knowledge dari tempat yang lama. Hal inilah yang menyebabkan penerapan Knowledge Management System (KMS) menjadi penting dikoperasi.

Pengetahuan atau knowledge merupakan hal penting yang harus dikelola oleh HRD dan karyawan untuk dapat meraih tujuan kemajuan koperasi dan agar dapat bersaing dalam dunia usaha. Perkembangan ilmu pengetahuan dan teknologi dapat memberikan banyak kemudahan dalam pengelolaan pengetahuan atau knowledge management dari koperasi. Kualitas sumber daya manusia dapat dipengaruhi tingkat perkembangan koperasi.

Menurut Davidson Carl \& Phlip Voss (2003) Mengelola Knowledge sebenarnya merupakan bagaimana organisasi mengelola staf mereka dari pada beberapa lama mereka menghabiskan waktu untuk teknologi informasi.

Koperasi Pegawai Bulog ( KOPEL) merupakan perusahaan sedang berkembang yang bergerak dibidang Simpan Pinjam. Salah satu dari visi Koperasi Pegawai Bulog (KOPEL) adalah bertekad untuk meningkatkan jasa pelayanan yang baik dengan adanya dukungan Sumber Daya manusia (SDM) yang sangat berpotensi. Sekarang ini Koperasi Pegawai Bulog (KOPEL) harus mencari trobosan baru inovatif didukung pengetahuan (Knowledge) yang sangat tinggi dan yang cukup.kepada pemilikan daya saing koperasi terhadap para pesaingnya. Pengetahuan atau knowledge merupakan hal penting yang harus dikelola oleh HRD dan karyawan untuk dapat meraih tujuan kemajuan koperasi dan agar dapat bersaing dalam dunia usaha. Perkembangan ilmu pengetahuan dan teknologi dapat memberikan banyak kemudahan dalam pengelolaan pengetahuan atau knowledge management dari koperasi. Kualitas sumber daya manusia dapat dipengaruhi tingkat perkembangan koperasi.

Memberikan metode mengubah informasi menjadi pengetahuan melalui kegiatan:comparation, consequences, connections, dan conversation (Samidi,2008):

a. Comparison: untuk membandingkan informasi pada berbagai kondisi

b. Consequences: konsekuensi apa informasi menyiratkan keputusan dan tindakan

c. Connections: hubungan apa antara pengetahuan dan informasi yang dihasilkan oleh bagian lain dari pengetahuan.

d. Conversations: dengan komunikasi langsung dengan orang lain untuk mendapatkan komentar mereka ke informasi

Menurut Nonaka, I \& Takeuchi, H (1995) , Untuk meningkatkan kualitas sumber daya manusia dibutuhkan knowledge management yang baik, Faktor yang paling penting dalam menjaga kualitas dari pengetahuan dalam proses Knowledge Management System (KMS) adalah pengetahuan yang akan dipergunakan sebagai dasar transfer ilmu pengetahuan, menyelesaikan melakukan inovasi Koperasi.mengusulkan empat mode transfer pengetahuan dan penciptaan (dikenal sebagai model SECI

Sosialisasiadalah proses berbagi pengalaman dan dengan demikian menciptakan pengetahuan tacit seperti model mental dan keterampilan teknis. Pengetahuan tacit dapat diperoleh tanpa menggunakan bahasa melalui observasi, imitasi, dan praktek.

Eksternalisasi adalah proses mengartikulasikan pengetahuan tacit dalam bentuk eksplisit konsep, mengambil bentuk metafora, analogi, konsep, hipotesis, atau model.

Combinasi adalah proses systemizing konsep ke dalam sistem pengetahuan dengan menggabungkan 
benda yang berbeda dari pengetahuan eksplisit. Eksplisit pengetahuan ditransfer melalui media seperti dokumen, pertemuan, dan e-mail dan / atau telepon percakapan. Kategorisasi pengetahuan ini dapat menyebabkan generasi pengetahuan baru. Internalisasi adalah proses konversi pengetahuan eksplisit ke dalam pengetahuan tacit dan erat kaitannya dengan learning by doing.

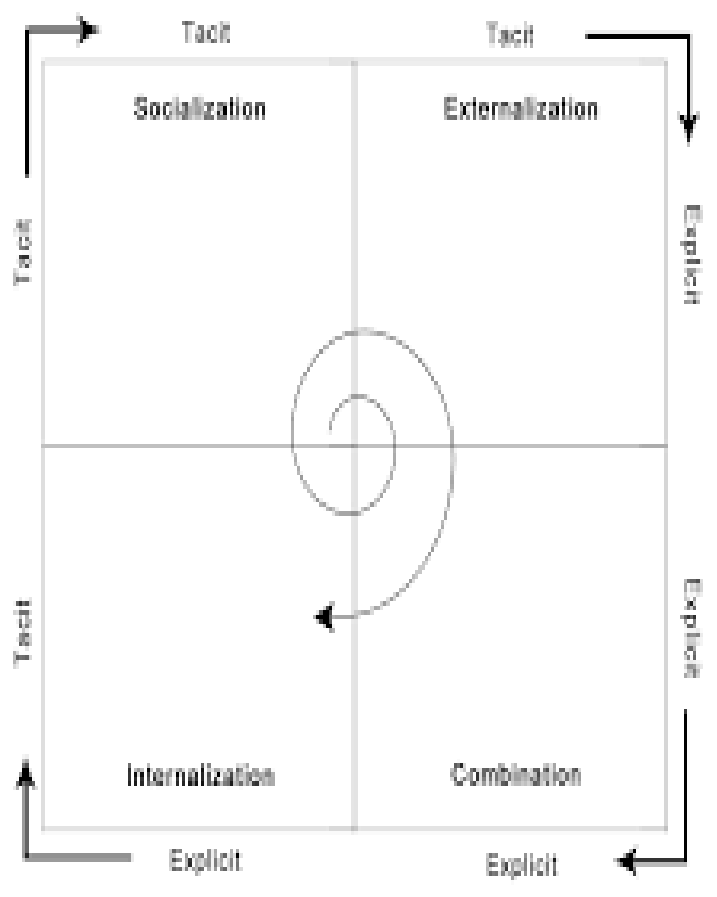

Gambar 1 Diagram SECI -Nonaka

Sumber : (Nonaka \& Takeuchi 1995)

Nonaka \& Takeuchi (1995) Mengatakan bahwa mengelola knowledge sebenarnya merupakan cara bagaimana organisasi mengelola karyawan mereka. Mengidentifikasikan pengetahuan yang dimiliki oleh karyawan. Menyimpan dan membaginya di tim, meningkatkan dan terjadinya inovasi. Sebenarnya menurut mereka bahwa knowledge management adalah bagaimana orang-orang dari berbagai tempat yang berbeda mulai saling bicara. Dimana sekarang yang paling popular untuk digunakan adalah label learning organization

Menurut Yuliazmi (2005) untuk memudahkan pengembangan sumber daya manusia perusahaan diperlukan kemampuan untuk mengelola dan mengembangkan knowledge yang dimiliki. Pengelolaan pengetahuan (Knowledge
Management) tersebut pada akhirnya dapat menjadi dukungan yang handal bagi perusahaan untuk meningkatkan daya saing

Menurut Bambang Setiarso (2006) Knowledge management yang sukses tidak hanya karena komputer yang impresif tetapi sebaiknya mengandung komponenkomponen, yaitu :

a. Alur knowledge yang benar dan sumber yang dilimpahkan ke organisasi.

b. Teknologi tepat yang disimpan dan dapat mengomunikasikan knowledge tersebut.

c. Budaya tempat kerja yang benar sehingga karyawan termotivasi untuk memanfaatkan knowledge

Menurut Hamdani (2011), pengembangan Model Knowledge Management System pada Biro umum dan sumber Manusia Yayasan Pendidikan Budi Luhur, Penelitianna Saat ini knowledge yang ada Biro Umum dan SDM berkembang secara lamban dan cendrun statis, itu terjadi karana beberapa alasan yaitu : pertama, hanya ada satu orang yang memiliki knowledge untuk, menyelesaikan berbagai macam perrmasalahan, kedua tidak adanya panduan atau buku manual untuk pegawai yang lain dalam menyelesaikan setiap permasalahan yang terjadi, ketiga: masa kerja yang tidak pasti, ke- empat, komunikasi diantara pegawai tidak terjalin dengan baik dan kelima proses sosialisasi aturan-aturan yang ada saat ini elum berjalan dengan efektif.

Dalam penelitian tersebut penulis menggunakan kerangka kerja model Tiwana dan pemetaan potensi knowledge organisasi menggunakan model Zack, dan untuk pembentukan knowledge menggunakan model SECI.

Menurut Ikojiro Nonaka (2008) "Pengetahuan baru timbul karena adanya Interaksi secara terus menerus antara pengetahuan explicit (teraktualisasi) dan tacit (terpen- dam)".

Menurut Bambang

Menjelaskan sasaran umum dari sistem manajemen pengetahuan dalam praktiknya adalah sebagai berikut:

a. Menciptakan pengetahuan

Pengetahuan diciptakan begitu manusia menentukan cara baru untuk melakukan sesuatu atau menciptakan know how

b. Menangkap pengetahuan 
Pengetahuan baru diidentifikasi sebagai bernilai dan diintepretasikan dalam suatu cara yang masuk akal.

c. Menjaring pengetahuan

Pengetahuan baru harus ditempatkan dalam konteks agar dapat ditindak lanjuti.

d. Menyimpan pengetahuan

Pengetahuan yang bermanfaat harus disimpan dalam format yang baik dalam penyimpanan pengetahuan sehingga orang lain dalam organisasi dapat mengaksesnya.

e. Mengolah pengetahuan

Pengetahuan harus diperbaharui apakah relevan dan akurat.

f. Menyebar luaskan pengetahuan

\section{Tacit Knowledge (TO) Explicit Knowledge}

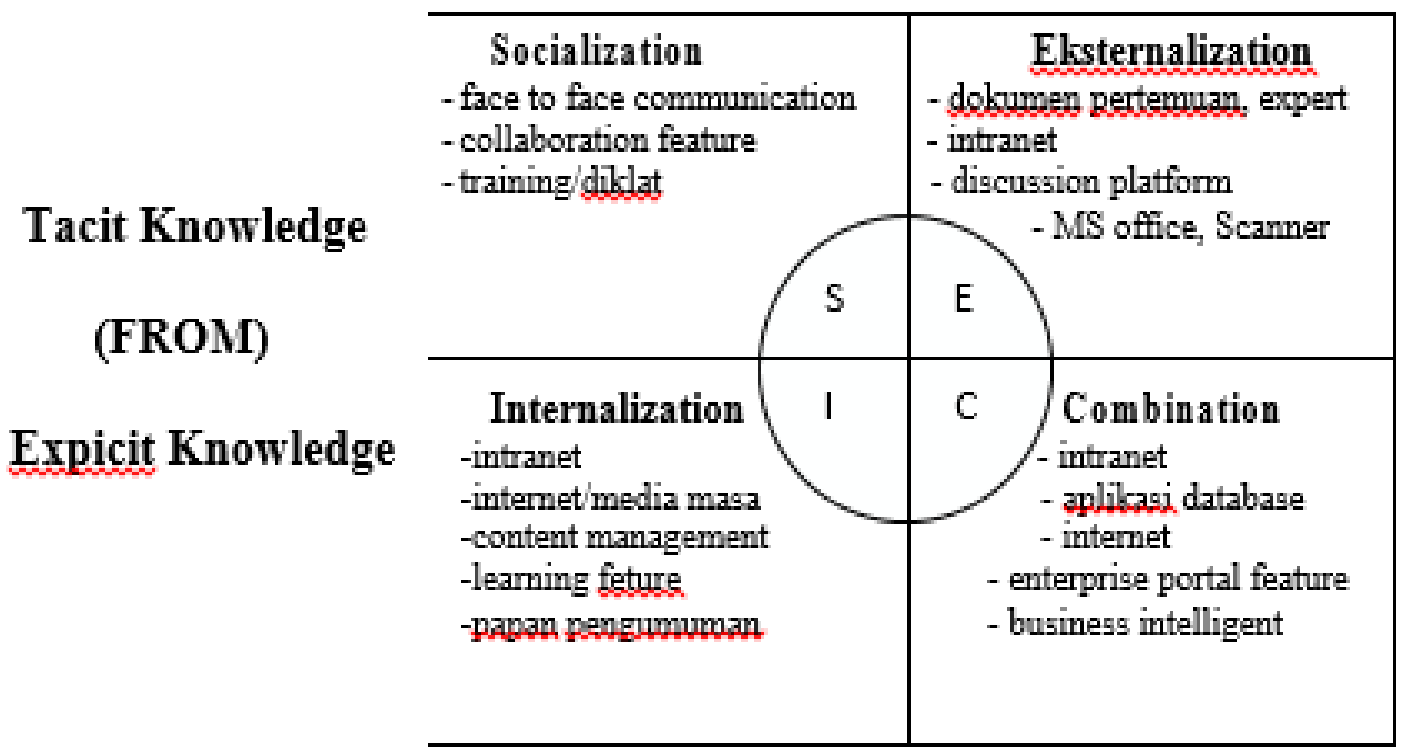

Gambar 2. Pemetaan proses SECI Model

Sumber: Thomas H Davenport \& I Prusak (1998)

\section{Metode Penelitian}

Berdasarkan tahapan SECI Model, tahap. Socialization satu proses dengan pertemuan tatap muka (rapat, diskusi dan pertemuan bulanan). Melalui pertemuan tatap muka ini individu dapat saling berbagi pengetahuan dan pengalaman yang dimilikinya sehingga tercipta pengetahuan baru. $\mathrm{Di}$ dalam sistem manajemen pengetahuan, fitur-fitur kolaborasi seperti email, diskusi elektronik, komunitas praktis (communities of practice) memungkinkan pertukaran pengetahuan tacit (informasi, pengalaman dan keahlian) yang dimiliki seseorang sehingga organisasi semakin mampu belajar dan melahirkan ide-ide baru yang kreatif dan inovatif. Hal ini baik untuk dilakukan karena bermanfaat untuk meningkatkan koordinasi, mempercepat proses aktivitas dan menumbuhkan budaya belajar. Proses sosialisasi juga dapat dilakukan melalui pendidikan dan training / diklat dengan mengubah pengetahuan tacit trainer menjadi pengetahuan tacit karyawan.

Pada tahapan Externalization merupakan proses yang bertujuan untuk mengartikulasi tacit knowledge menjadi suatu konsep yang jelas atau eksplisit melalui proses dialog dan refleksi. Dukungan terhadap proses eksternalisasi dapat diberikan dengan mendokumentasikan notulen rapat (bentuk eksplisit dari knowledge yang tercipta saat diadakannya pertemuan) kedalam bentuk elektronik untuk kemudian disimpan dalam suatu repository dan dipublikasikan kepada pihak yang berkepentingan, sehingga bisa dikembangkan dan dimanfaatkan untuk meningkatkan knowledge atau kompetensi karyawan.

Pada tahapan Combination yaitu Proses mengkombinasikan berbagai explicit knowledge yang berbeda untuk disusun ke dalam sistem knowledge management. Media untuk proses ini dapat melalui intranet (forum diskusi), database 
organisasi dan internet untuk memperoleh sumber eksternal. Fitur-fitur Enterprise Portal seperti knowledge organization system yang memiliki fungsi untuk pengategorian informasi (taksonomi), pencarian dan sebagainya membantu dalam proses ini. Business Intellegence sebagai fungsi penganalisis data secara matematis dapat digunakan untuk pengambilan keputusan. Data yang telah tersimpan dalam sistem (data warehouse) dianalisis terutama untuk kondisi yang bersifat strategis. Content Management yang memiliki fungsi untuk untuk mengelola informasi organisasi baik yang bersifat terstruktur (database) atau tidak terstruktur (dokumen, laporan, notulen) juga mendukung proses kombinasi ini.

Pada Internalization yaitu semua dokumen data, informasi dan pengetahuan yang sudah didokumentasikan dapat dibaca oleh orang lain. Proses internalisasi inilah terjadi peningkatan knowledge sumber daya manusia. Sumber- sumber explicit knowledge dapat diperoleh melalui media intranet (database organisasi), surat edaran/surat keputusan, papan pengumuman dan internet serta media massa sebagai sumber eksternal.

Hasil interpretasi dari setiap item pertanyaan yang digunakan dalam kuisioner ditentukan berdasarkan rentang skala dengan rumus yaitu:

Rentang Skala $=$

SMak - SMin $=R$

\begin{tabular}{|c|c|}
\hline BSk & BK \\
\hline Dimana: & \\
\hline SMak & = Skor Maksimal \\
\hline SMin & $=$ Skor Minimal \\
\hline $\mathrm{R}$ & $=$ Rentang \\
\hline BSK & = Besar Skala \\
\hline BK & $=$ Banyak Kelas \\
\hline$P$ & $=$ Panjang kelas interval \\
\hline $\begin{array}{l}\text { Rentang } \\
\text { terkecil }\end{array}$ & $=$ Data terbesar- Data \\
\hline $\begin{array}{l}\text { Banyak Kelas } \\
\text { Jadi, panjang k€ }\end{array}$ & $\begin{array}{l}=5 \\
\text { elas interval adalah } \mathrm{P}=5-1\end{array}$ \\
\hline
\end{tabular}

0,8

Penelitian ini menggunakan skala likert 1 sampai 5, sehingga berdasarkan rumus didapatkan nilai skor rata-rata yang diperoleh sebesar 0.79. Maka rentang skala yang diperoleh untuk interpretasi hasil jawaban kuesioner dapat dilihat pada Tabel 1.
Tabel 1. Rentang Skala Interpretasi hasil Jawaban Kuesioner

\begin{tabular}{|l|l|l|}
\hline $\begin{array}{l}\text { Rentang } \\
\text { Skala }\end{array}$ & $\begin{array}{l}\text { Pernyataan } \\
\text { Jawaban }\end{array}$ & $\begin{array}{l}\text { Interpretasi } \\
\text { hasil }\end{array}$ \\
\hline $1.00-1.79$ & $\begin{array}{l}\text { Sangat } \\
\text { Tidak } \\
\text { Setuju }\end{array}$ & $\begin{array}{l}\text { Sangat Tidak } \\
\text { Setuju }\end{array}$ \\
\hline $1.80-2.59$ & $\begin{array}{l}\text { Tidak } \\
\text { Setuju }\end{array}$ & Tidak Baik \\
\hline $2.60-3.39$ & Netral & Cukup \\
\hline $3.40-4,19$ & Setuju & Baik \\
\hline $4,20-5.00$ & $\begin{array}{l}\text { Sangat } \\
\text { Setuju }\end{array}$ & Sangat Baik \\
\hline
\end{tabular}

Sumber : Hasil dari penelitian 2015

Penelitian menggunakan metode Deskriptif Kualitatif dan Metode ini digunakan dengan maksud untuk mempelajari secara instensif dan mendalam tentang latar belakang masalah yang ada pada obyek penilitian yaitu mengembangkan knowledge management system. Hasil dari penelitian ini adalah sebuah mengembangkan Knowledge Management System yang diusulkan dan diterapkan pada koperasi.

Langkah - langkah metodologi penelitian sebagai berikut:

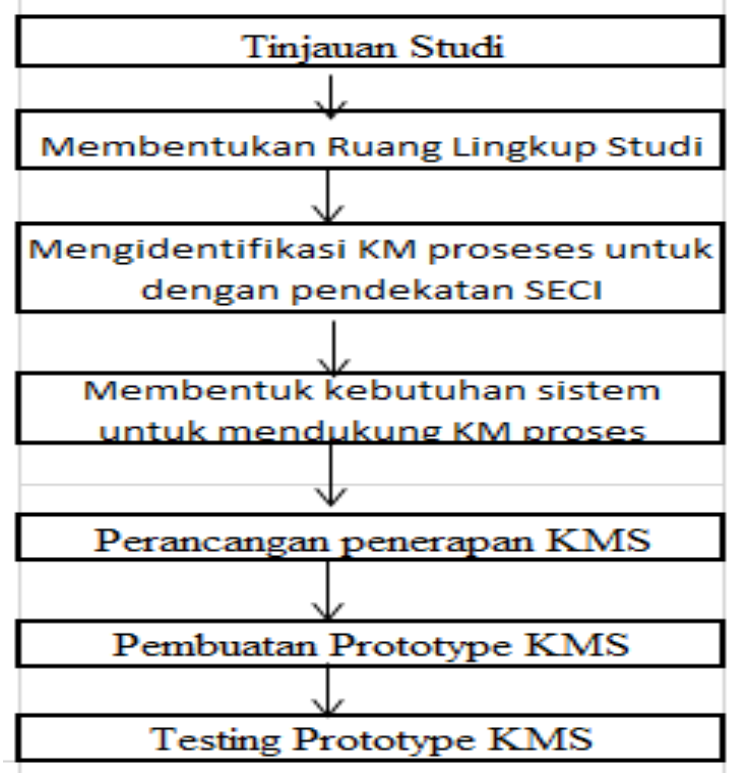

Gambar 3 Langkah -langkah Penelitian Sumber : Penelitian 2015 
Mengindentifikasi KM Proses untuk dengan pendekatan SECI

Tahapan terdiri dari 4 tahapan proses yaitu:

a. Proses Socialization (tacit to Tacit) Proses ini mengubah tacit knowlege menjadi tacit knowledge lainnya , misalnya belajar dari karyawan yang lebih berpengalaman. Proses inii membuat pengetahuan kita semakin berkembang dan penting untuk peningkatan diri sendiri. Proses ini nantina akan berputar pada proses eksternalisasi. Semakun sukses kita mengalami proses tacit knowledge baru, semakin banyak explicit knowledge yang berhasil kita produksi pada proses eksternalisasi.

b. Proses Externalization (Tacit to Explicit). Proses yan terjadi pada tahapan ini mengubah tacit knowledge yang kita miliki menjadi explicit knowledge. Dapat diperoleh dengan cara menuliskan knowknow dan pengalaman yang kita dapatkan dalam bentuk tulisan artikel atau bahan dari buku. Tulisan-tulisan tersebut sangat bermanfaat bagi orang lain yang sedang memerlukan. Cara yang paling efektif untuk dilakukan pada proses externalization adalah melelui dialog.

c. Proses Combination (Explicit to Explicit).Proses combination yaitu memanfaatkan explicit knowledge yangada kemudian diimplementasikan menjadi explicit knowledge lain. Proses ini berguna untuk meningkatkan skill dan produktifitas diri sendiri. Melalui proses ini juga dapat mengkombinasikan explicit knowledge yang menjadi explicit knowledge baru yang lebih bermanfaat

d. Proses Internalization (Explicit to Tacit)

Proses ini mengubah explicit knowledge sebagai insprirasi datangnya tacit knowledge. Dari keempat proses yang ada, dapat dikatakan bahwa prose ini yang telah dilakukan. Bahasa lainnya adalah learning bay doing. Dengan refensi baru, pemahaman baru, dan know-know baru yang tidak saya dapatkan dari buku tersebut.

\section{Testing Prototype Knowledge Management System \\ Testing Prototype Knowledge}

Management System dilakukan dengan memcoba melakukan proses-proses Knowledge Management System yang didukung oleh prototype mengembangkan knowledge management system. Testing dilakukan pada forum diskusi dengan menggunakan skenario knowledge yang dibutuhkan.

\section{Uji Coba Prototype Knowledge Management System}

Uji coba ini dilakukan oleh karyawan pada koperasi, yang digunakan adalah sharing knowledge dengan mengcapture tacit dan explict knowldge menggunakan modul yang ada pada prototype knowledge management system.

1. Sharing tacit knowledge.

Pada sharing ini menggunakan forum/ diskusi. Dengan menggunakan modul forum ini setiap karyawan dapat berbagai ide, pengalaman atau menanyakan tentang sessuatu hal kepada HRD. Seorang karyawan ingin mengetahu peraturan yang ada misalnya mengenai tentang cuti, atau yang lainnya. Dan dari pihal HRD akan menjawab pertanyaan karyawan. Kesimpulannya dari uji coba ini adalah proses sharing knowledge dengan menggunakan modul forum dapat berjalan dengan baik. Dari forum ini terjadi proses Sosialisasi ( tacit menjai tacit) dan eksternalisasi ( tacit menjadi explicit)

2. Sharing explicit knowledge

Pada modul manajemen dokumen. Karyawan ingin melakukan sharing knowledge dengan mengupload informasi yang terbaru. Dan setelah itu user admin membalas pertanyaan dan memberikan jawaban yang ada, karyawan dapat mendownload dokument tersebut.Kempulan dari uji coba ini adalah proses sharing knowledge dengan menggunakan model manajemen dokumen berjalan dengan baik.Dari forum tersebut terjadi proses eksternalisasi (tacit menjadi explicit) dan internalisasi ( explicit menjadi tacit)

\section{Hasil dan Pembahasan}

\subsection{Analisa Proses KM yang sudah ada di koperasi}

Analisa ini dilakukan melalui wawancara yang dilakukan dan uji coba aplikasi kepada karyawan. Selama ini 
koperasi dalam menyelesaikan permasalahan yang terjadi, biasanya dengan melaukan pertemuan, diskusi atau bertukar informasi tentang pengetahuan. Dari kebiasaan-kebiasan yang terlihat maka dapat dikatakan suatu proses sosialisasi, eksternalisasi, kombinasi dan internalisasi.

Pada proses eksternalisasi belum sampai pada pembuatan dokumen dari pengalaman yang didapatkan oleh Sumber Daya Manusia (SDM) dan HRD dalam menyelesaikan suatu permasalahan dilapangan.

Selanjutnya proses internalisasi sudah dilaksanakan tetapi belum sampai pada tahap para karyawan dengan mudah mendapatkan pengetahuan

Tabel 2. Proses Knowledge Management dari kegiatan Koperasi

\subsection{Perancangan Penarapan Knowledge Management System}

Proses-proses dari Knowledge

Management System adalah eksternalisasi dan internalisasi. Sementara proses sosialisasi dan kombinasi sudah berjalan cukup baik namun masih ada kekurangannya. Mengembangkan Knowledge management system di koperasi sebagai berikut:

a. Proses Sosialisasi

Proses sosialisasi ini adalah proses untuk dapat mengubah knowledge yang bersifat tacit menjadi tacit kembali. Dengan ini akan mempermudah proses komunikasi karena karyawan tidak harus menunggu untuk saling bertemu secara langsung untuk bertanya dan mendiskusian penyelesaian suatu permasalahan

b. Proses Eksternalisasi

Proses eksternalisasi adalah proses untuk dapat mengubah knowledge yang bersifat tacit menjadi explicit. Fitur yang mendukung adalah pada diskusi. Dengan diskusi ini semua ide atau pengalaman dapat dituliskan diforum diskusi tersebut dan kemudian dapat dibaca oleh karyawan lain. Fprum diskusi ini dapat berupa pengalaman dalam pekerjaan dan peraturan yang ada, juga adanya solusi dalam menangani permasalahan dikoperasi.

c. Proses Kombinasi

Proses kombinasi adalah proses yang dilakukan untuk mengubah knowledge yang berrsifat explicit menjadi explicit. Fitur yang mendukung adalah menajemen dokumen baik berupa upload atau download. Dengan fitur ini para karyawan dapat menambil explicit knowledge yang ada. Tabel ProsesProses Knowledge Management System dan teknologinya

d. Proses Internalisasi

Proses internalisasi adalah proses untuk dapat megubah knowledge yang berrsifat explicit menjadi taci. Fitur yang mendukung adalah diskusi dan manajemen dokumen. Dengan ini semua ide atau pengalaman dari karyawan dapat dibaca dan dipahami oleh para karyawan yang lain dengan mudah. Manajemen dokumen juga dapat membantu proses internalisasi karena karyawan dapat mudah melihat semua dokument yang ada pada konsep knowledge menagement system ini.

\begin{tabular}{|l|l|l|l|}
\hline No & Kegiatan & $\begin{array}{l}\text { Pelaksa } \\
\text { naan }\end{array}$ & Proses KM \\
\hline 1 & $\begin{array}{l}\text { Pengalaman } \\
\text { dalam untuk } \\
\text { menyelesaiak } \\
\text { an suatu } \\
\text { permasalah } \\
\text { yang ada }\end{array}$ & $\begin{array}{l}\text { Sharing } \\
\text { knowled } \\
\text { ge } \\
\text { Diskusi }\end{array}$ & $\begin{array}{l}\text { Sosialisasi } \\
\text { Eksternalisa } \\
\text { si } \\
\text { Kombinasi }\end{array}$ \\
\hline 2 & $\begin{array}{l}\text { Pembuatan } \\
\text { dokumen }\end{array}$ & $\begin{array}{l}\text { Sharing } \\
\text { dokumen } \\
\text { Diskusi }\end{array}$ & $\begin{array}{l}\text { Sosialisasi } \\
\text { Eksternalisa } \\
\text { si } \\
\text { Kombinasi } \\
\text { Internalisasi }\end{array}$ \\
\hline 3 & $\begin{array}{l}\text { Pengalaman } \\
\text { mengikuti } \\
\text { training } \\
\text { knowledge } \\
\text { management }\end{array}$ & $\begin{array}{l}\text { Sharing } \\
\text { knowled } \\
\text { ge } \\
\text { Sharing } \\
\text { dokumen }\end{array}$ & $\begin{array}{l}\text { Sosialisasi } \\
\text { Eksternalisa } \\
\text { si } \\
\text { Kombinasi } \\
\text { Internalisasi }\end{array}$ \\
\hline
\end{tabular}

Tabel 3. Poses Knowledge Management System dan Teknologi

\begin{tabular}{|l|l|l|}
\hline No & $\begin{array}{l}\text { Proses } \\
\text { Knowledge } \\
\text { Managemen } \\
\mathrm{t}\end{array}$ & Teknologi \\
\hline 1 & Sosialisasi & Diskusi Eletronik \\
\hline 2 & $\begin{array}{l}\text { Eksternalisa } \\
\text { si }\end{array}$ & $\begin{array}{l}\text { Diskusi Electronik } \\
\text { Manajement } \\
\text { dokumen }\end{array}$ \\
\hline 3 & Kombinasi & $\begin{array}{l}\text { Manajemen } \\
\text { dokumen }\end{array}$ \\
\hline 4 & Internalisasi & $\begin{array}{l}\text { Diskusi Electronik } \\
\text { Manajemen } \\
\text { dokumen }\end{array}$ \\
\hline
\end{tabular}

Teknologi sangat berperan dalam membantu terjadinya proses knowledge management. Berikut ini adalah fitur teknologi yang dapat dipergunakan untuk mendukung proses knowledge management system 
Tabel 4 Kegiatan pada Teknologi Knowledge Management System

\begin{tabular}{|l|l|l|}
\hline No & \multicolumn{1}{|c|}{ Teknologi } & \multicolumn{1}{|c|}{ Kegiatan } \\
\hline 1 & Forum diskusi & $\begin{array}{l}\text { Membuat Forum } \\
\text { Diskusi, Membuat } \\
\text { topik, membahas } \\
\text { topik, membuat } \\
\text { tanya jawab topik } \\
\text { yang ada. }\end{array}$ \\
\hline 2 & $\begin{array}{l}\text { Manajemen } \\
\text { dokumen } \\
\text { diupload dokumen } \\
\text { dan download } \\
\text { dimasukan } \\
\text { dalam artikel di }\end{array}$ \\
\hline
\end{tabular}

\subsection{Arsitektur Knowledge Management System}

Berikut ini penjelasan dari Arsitektur mengembangkan Knowledge Management System:

1. Karyawan harus register dahulu, stelah itu masuk kelogin, barulah membuka aplikasi untuk dapat menjalankannya.
2. Access and Authentications Layer Keamanan data dari knowledge management system harus dijaga dan proses login sebagai langkah untuk otentifikasi agar hanya yang terdaftar atau yang berhak saja yang dapat menggunakan knowledge management system ini,

3. Application Layer Apache untuk databasenya digunakan untuk mendukung berjalannya aplikasi ini.

4. Repositories

Databese yang digunakan adalah Xampp, untuk menyimpan data dan folder khusus untuk menyimpan dokumen-dokumen yang dipakai berkolaborasi oleh para karyawan.

\subsection{Class Diagram.}

Class diagram yang digunakan untuk pengembangan penerapan dapat dilihat pada gambar sebagai berikut:

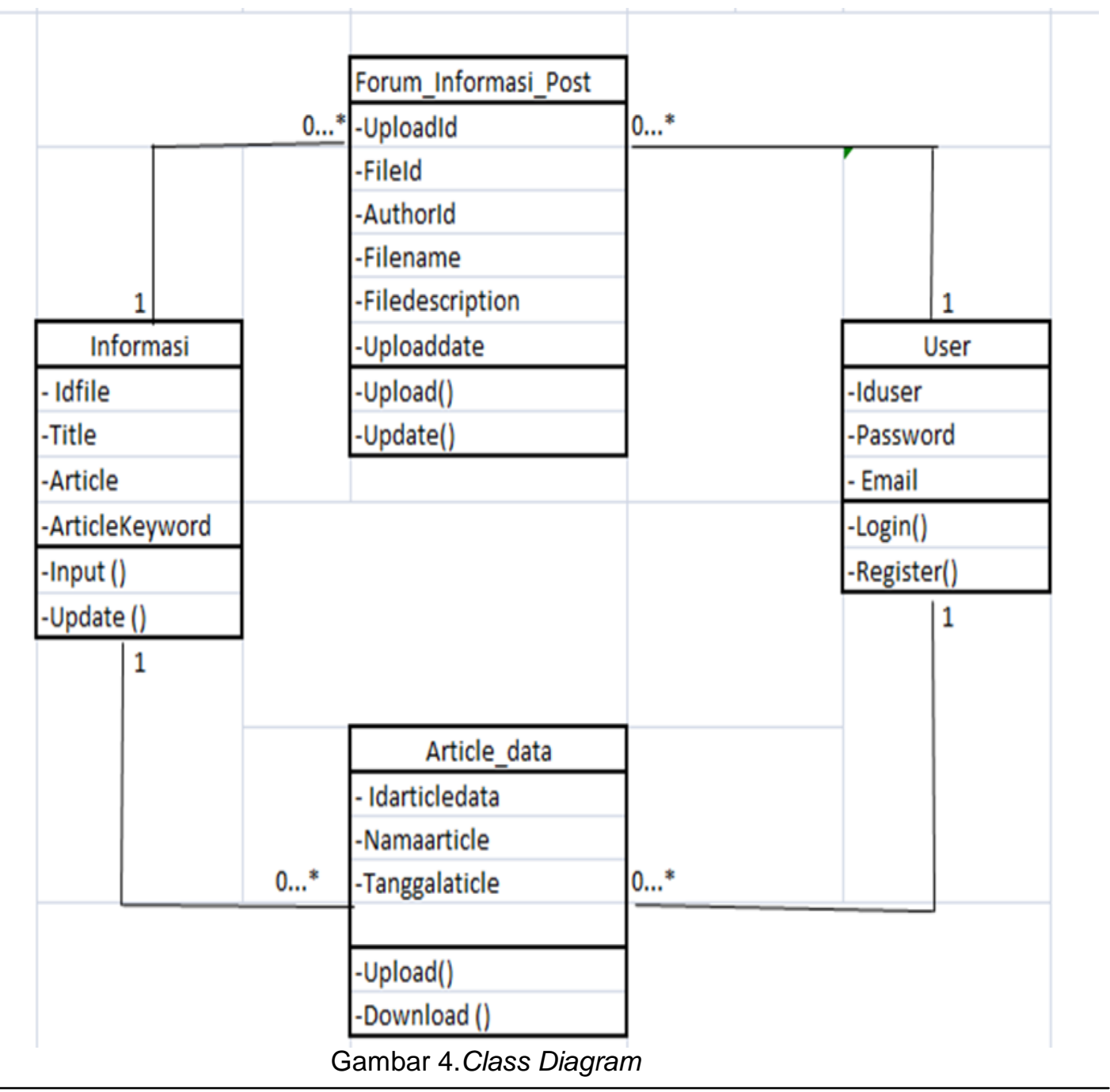

JURNAL INFORMATIKA Vol.5 No.1, April 2018: 157-168 


\subsection{Tampilan dari Knowledge Management System}

a. Register

Halaman ini berisikan tentng proses register, bagi yang ingin melihat aplikasi ini, dan agar mendapatkan login.

b. Login

Halaman ini berisikan proses login.

c. Menu

Halaman ini hanyanya terdapat data saja.

d. Lihat knowledge

Dapat melihat tentang knowledge yang sudah ada khususnya yang sudah diposting dan diapprove oleh administrator.

e. Tambah knowledge Halaman ini berisikan tentang knowledge yang ingin menambahkan data tentang data perusahaan.

f. Forum/Diskusi/Quistion

\subsection{Antar Muka Halaman Utama}

Antar muka ini merupakan tampilan awal sekaligus tampilan utama dari
Halaman ini hanya berisikan tentang forum bertanya, dan yang mana semua karyawan dapat mengikuti forum yang telah disediakan,.

g. Ubah Informasi

Halaman ini berisikan tentang adanya perubahan data yang memang harus dirubah.

h. Upload Knowledge Halaman ini berisikan tentang upload data yang bisa dilakukan oleh karyawan, dan harus diapprove dulu oleh administrator.

i. Download Knowledge.

Halaman ini berisikan download data yang bisa dilakukan oleh user khususnya karyawan yang sudah login dan yang ingin mendownload data.

j. Logout.

Halaman ini untuk keluar dari menu

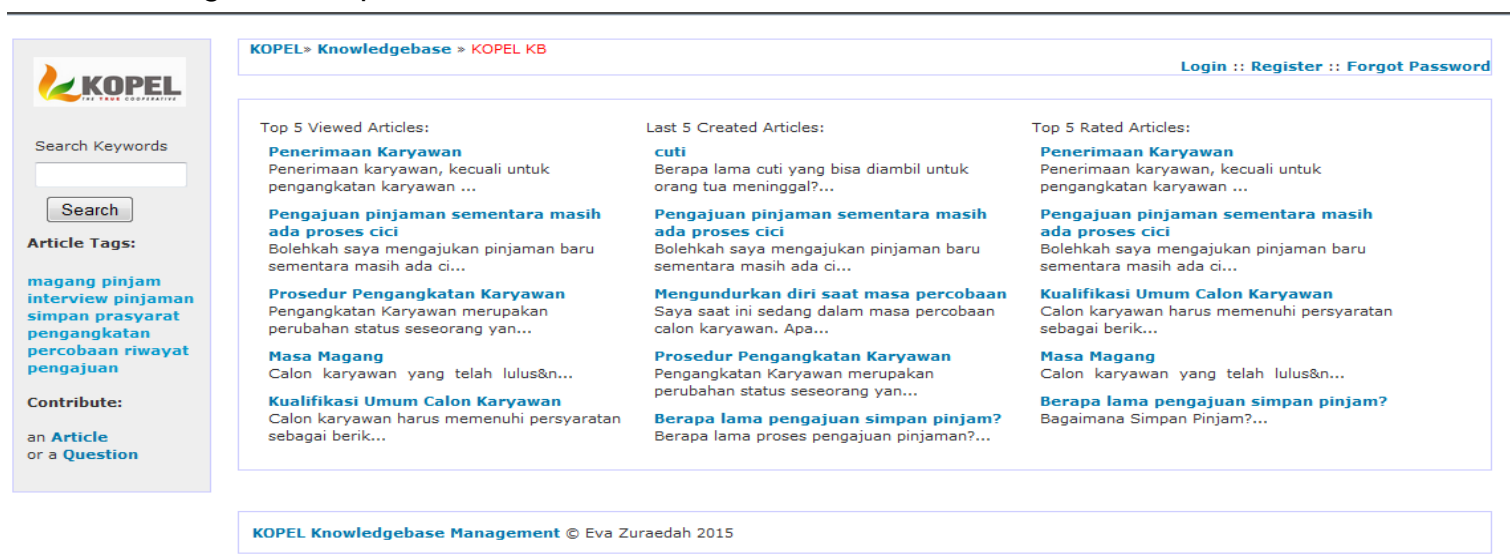

Gambar 6 Antar Muka Halaman Utama

3.7. Antar Muka Halaman Register

Antar Muka Halaman Register adalah karyawan harus register dahulu
Knowledge Management System (KMS) dari SOP terdiri dari :Login, Regiter, forgot Password, Search

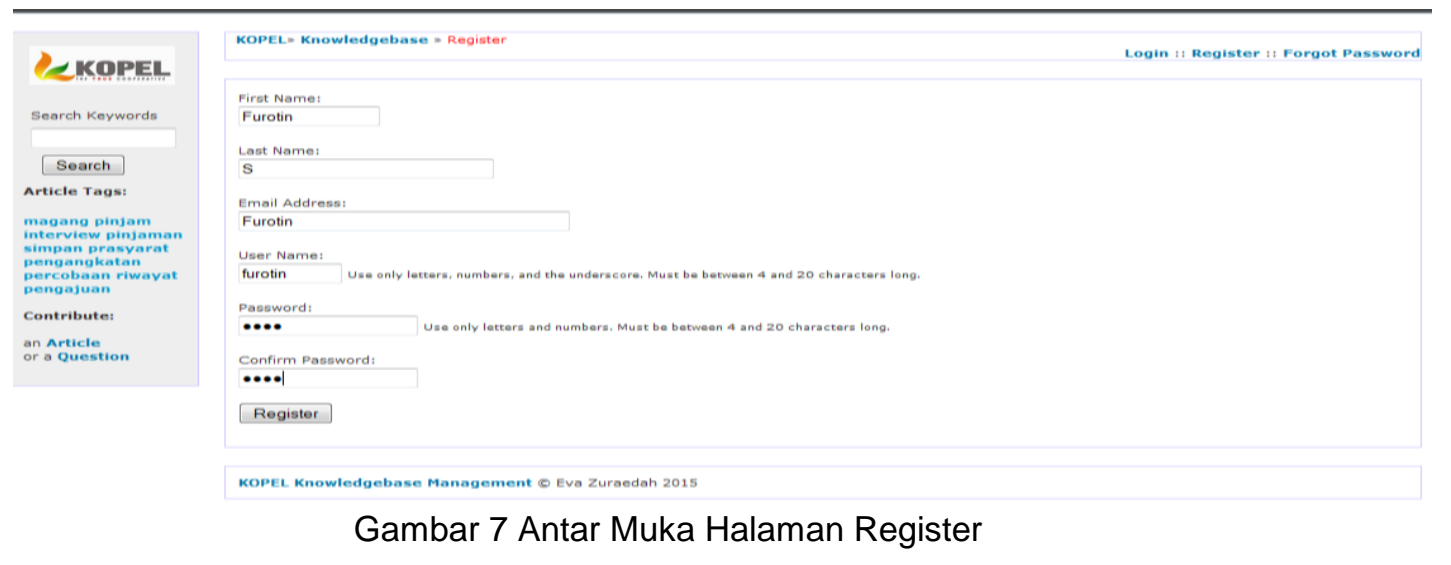




\subsection{Antar Muka Halaman Menambah Knowledge}

Antar muka halaman ini adalah untuk penambahan data yang diperlukan oleh koperasi.

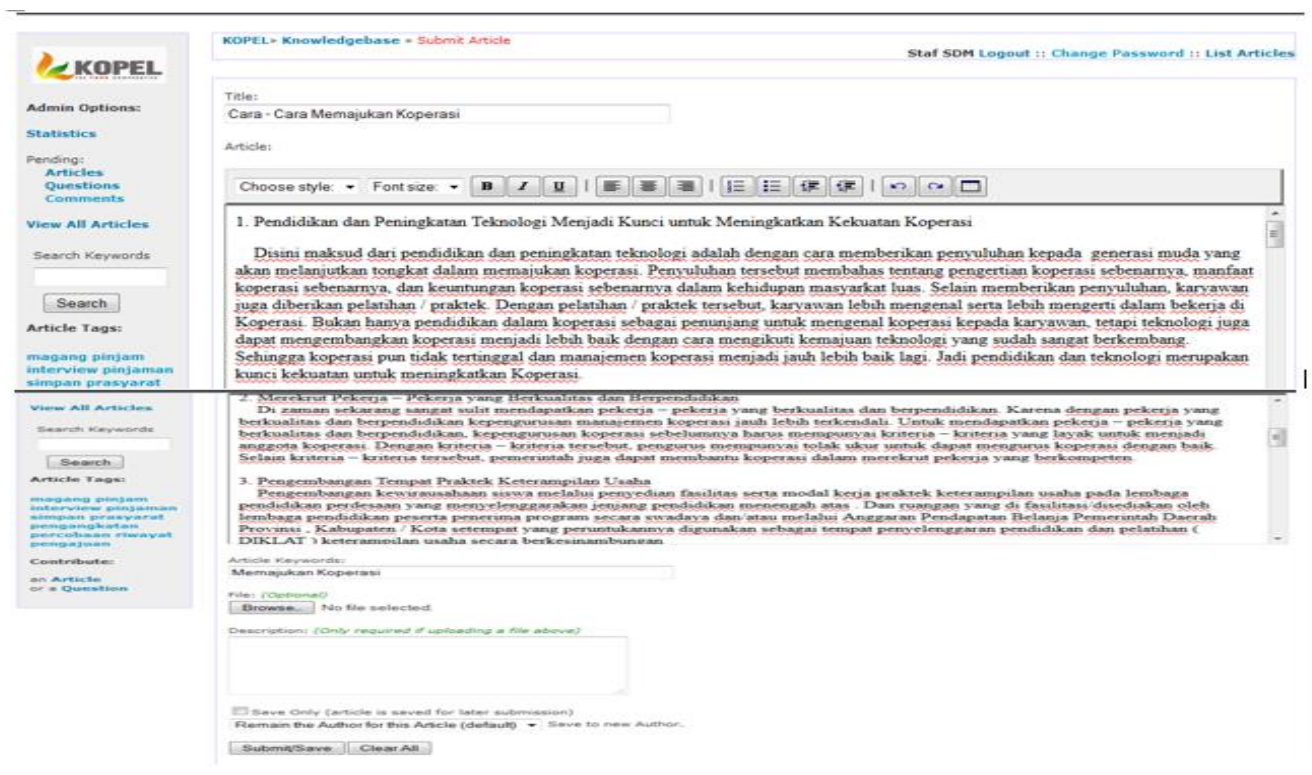

Gambar 8 Antar Muka Halaman Menambah Knowledge

\subsection{Antar Muka Hasil Dari Jawaban \\ Halaman antar muka dari Forum Diskusi Berdasarkan Penilaian. jawaban forum diskusi ini, adapun mendapatakan penilaian.}

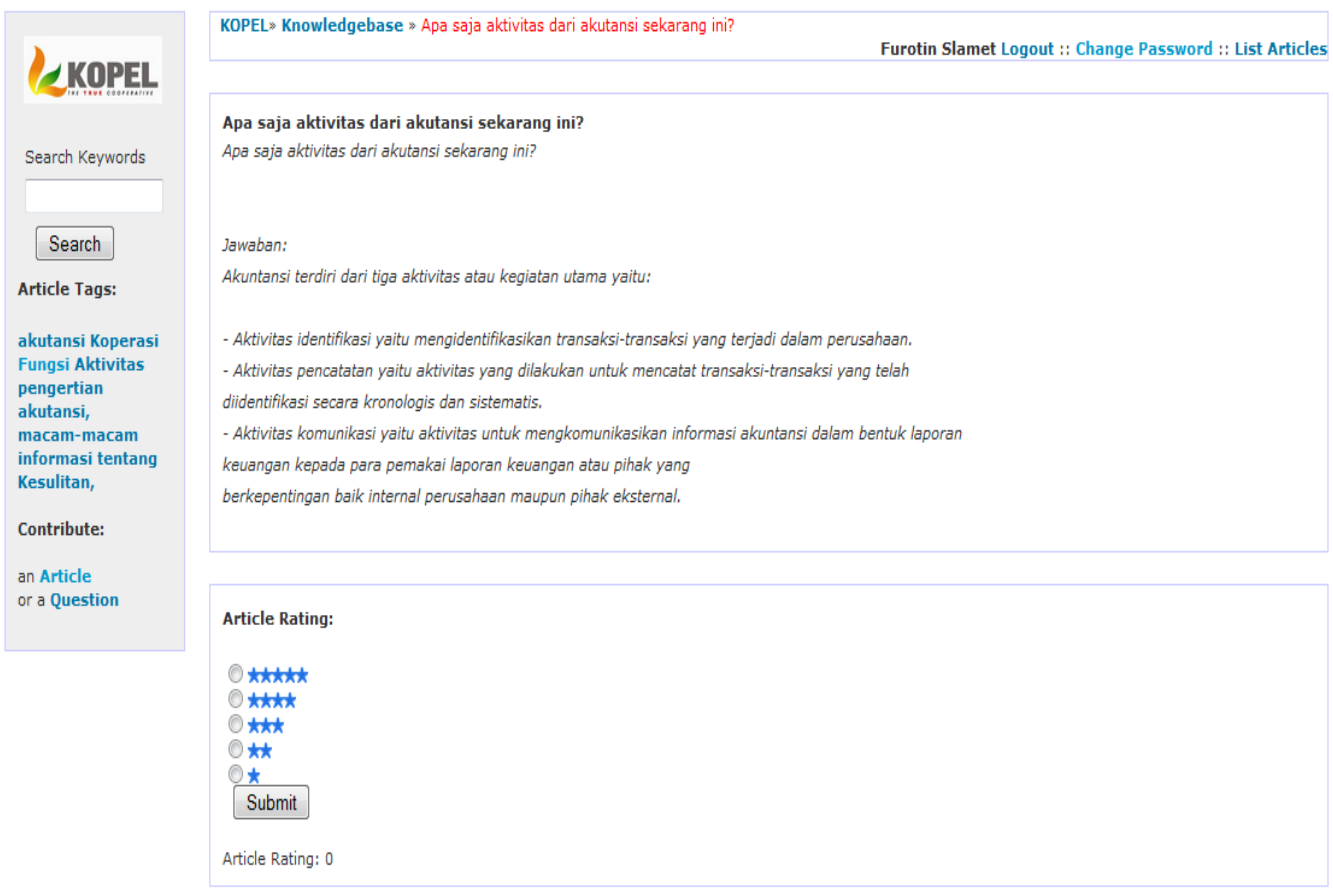

Gambar 9.

Antar Muka Hasil Dari Jawaban Forum Diskusi Berdasarkan Penilaian 


\subsubsection{Perhitungan Data survei KMS}

Tabel 5. Keterangan Jawaban Respondence

\begin{tabular}{|c|c|c|c|c|}
\hline $\begin{array}{c}\text { Kode } \\
\text { Jawa } \\
\text { ban }\end{array}$ & $\begin{array}{c}\text { Jawaban } \\
\text { Reponden }\end{array}$ & Skor & Interval & Keterangan \\
\hline SS & Sangat Setuju & 5 & $4,20-5$ & Sangat baik \\
\hline S & Setuju & 4 & $3,40-4,19$ & Baik \\
\hline N & Netral & 3 & $2,60-3,39$ & Cukup \\
\hline TS & Tidak Setuju & 2 & $1,80-2,59$ & Buruk \\
\hline STS & $\begin{array}{c}\text { Sangat Tidak } \\
\text { Setuju }\end{array}$ & 1 & $1,00-1,79$ & Sangat Buruk \\
\hline
\end{tabular}

a. Sosialisasi .

Hasil hitung dari wawancara kepada Ketua koperasi, manager dan karyawan untuk aktivitas KMS pada Koperasi Pegawai Bulog secara total, utuk skor total 679 , skor rata rata 48,50 , dengan 14 pertanyaan dan hasil yang didapat pada saat sekarang, Hasil hitung dari wawancara kepada Ketua koperasi, manager dan karyawan untuk aktivitas KMS pada Koperasi Pegawai Bulog secara total, utuk skor total 754 , skor rata rata 53,86, dengan 14 pertanyaan dan hasil yang didapat, pada kondisi yang diharapkan.

a. Eksternalisasi

Hasil hitung dari pengujian kepada anggota koperasi untuk aktivitas KMS pada Koperasi Pegawai Bulog secara total, utuk skor total 442 , skor rata rata 44,2 , dengan 10 pertanyaan dan hasil yang didapat.

b. Kombinasi

Hasil hitung dari pengujian kombinasi antara teknologi dan bisnis di koperasi yang didapat dari ketua koperasi, manager, dan masing divisi di koperasi untuk aktivitas KMS pada Koperasi Pegawai Bulog secara total, untuk skor total 674, skor rata rata56,16, dengan pertanyaan 12 dan hasil yang didapat dari teknologi, Hasil hitung dari pengujian kombinasi antara teknologi dan bisnis di koperasi yang didapat dari ketua koperasi, manager, dan masing divisi di koperasi untuk aktivitas KMS pada Koperasi Pegawai Bulog secara total, untuk skor total 586 , skor rata rata 53,27, dengan 11 pertanyaan dan hasil yang didapat dari bisnis.

\section{c. Internalisasi}

Hasil hitung dari pengujian dari applikasiuntuk internalsasi yang di uji coba di koperasi yang didapat dari ketua koperasi, manager, dan masing divisi di koperasi untuk aktivitas KMS pada Koperasi Pegawai Bulog secara total, untuk skor total 478 , skor rata rata 47,80 , dengan 10 pertanyaan dan hasil yang didapat dari bisnis.

\subsection{Hasil Pengujian aplikasi}

Hasil hitung dari pengujian dari applikasi yang di uji coba di koperasi yang didapat dari ketua koperasi, manager, dan masing divisi di koperasi untuk aktivitas KMS pada Koperasi Pegawai Bulog secara total, untuk skor total 728 , skor rata rata 48,53 , dengan 15 pertanyaan dan hasil yang didapat.

Berdasarkan dari pengujian applikasi yang telah dibuat dan juga diberikan beberapa pertanyaan diata, maka dapat disimpulkan bahwa Knowledge Management System dapat diterima dan berfungsi dengan baik.

\section{Kesimpulan}

Dari hasil penelitian yang dilakukan pada Koperasi Karyawan Bulog jakarta Selatan dengan pendekatan SECI, diperoleh sebuah KMS dengan fungsionality yang terdiri dari :

Forum diskusi : membuat forum diskusi, membuat topik, membahas topik, membuat tanya jawab topik yang ada, Manajemen dokumen : diuploadnya dokumen dan mendownload dokumen, dimasukan didalam artikel; Fasilitas untuk tanya jawab tentang masalah pekerjaan yang terkait dengan unit kerja; Fasilitas staf / admin untuk "approvel" terhadap knowledge yang dimasukan oleh karyawan; dan Fasilitas untuk mencari pengetahuan yang terkait dengan pekerjaan. 


\begin{abstract}
Perancangan sebuah Knowledge Management System pada KOPEL, sebagai bentuk penerapan KMS untuk komponen teknologi. KMS ini berhasil memfasilitasi terjadinya seluruh proses pengelolaan pengetahuan SECI, yaitu dimulai dari proses socialization, externalization, combination, dan internalization, serta menjamin keberlangsungan pengelolaan pengetahuan dan kelayakan pengetahuan. Dengan dikembangkan knowledge management system ini, karyawan dapat melakukan transfer pengetahuan antar karyawan, dan melakukan transfer pengetahuan kedalam knowledge management system berupa ide-ide knowledge pada basis pengetahuan yang bermanfaat.

Saran
\end{abstract}

Knowledge managament system yang dibangun dalam bentuk prototype masih merupakan model awal yang belum secara utuh memasukkan basis pengetahuan bagi koperasi. Dengan demikian basis pengetahuan yang ada didalam prototype knowledge management system ini perlu dikembangkan untuk dapat lebih efektif. Penerapan knowledge managment system ini perlu dikembangkan lagi untuk mendapatkan berkolaborasi dengan organisasi terkait, agar basis pengetahuan lebih luas dan transfer knowledge yang lebih efektif. Sistem perlu diuji secara berkala dan apabila diperlukan penambahan maupun perbaikan basis pengetahuan pada saat pengembangan perlu diperhatikan tingkat kerumitan akibat banyaknya jumlah pengetahuan yang akan tersimpan pada sistem.

Dilakukan penambahan secara berkala untuk dapat dilakukan pembaharuan baik secara mekanisme atau basis pengetahuan yang telah ada. Dilakukan penelitian lebih lanjut mengenai tingkat keinginan karyawan dalam berbagi ilmu pengetahuan. Penerapan sistem ini dibutuhkan pengetahuan kepada seluruh karyawan agar penggunaan sistem ini dapat berjalan dengan lancar dan sistem ini dapat memenihi semua kebutuhan yang ada. Tujuan dari diadakan pelatihan adalah agar karyawan memahami cara menggunakan sistem baru ini dan bagaimana knowledge management system (KMS) dapat membantu dalam kegiatan personalia introduction to creating competitive advantage from intellectual capital. Tandem press.

Davenport, T. H., \& Prusak, L. (1998). Working knowledge: How organizations manage what they know. Harvard Business Press.

Hamdani, A. U. (2016). Pengembangan Model Knowledge Management System pada Biro Umum Dan Sumber Daya Manusia Yayasan Pendidikan Budi Luhur. Telematika MKOM, 3(1), 27-39. https://journal.budiluhur.ac.id,

Nonaka, I., \& Takeuchi, H. (1995). The knowledge-creating company: How Japanese companies create the dynamics of innovation. Oxford university press.

Setiarso, B. (2003). Manajemen pengetahuan (knowledge management) dan proses penciptaan pengetahuan. IImu Komputer. com.

Setiarso, B. (2006). Pengelolaan pengetahuan (knowledge management) dan modal intelektual (intellectual capital) untuk pemberdayaan UKM. Lembaga IImu Pengetahuan Indonesia, Jakarta.

Tiwana, A. (2000). The knowledge management toolkit: practical techniques for building a knowledge management system. Prentice Hall PTR.

Yuliazmi. (2005:1). Penerapan Knowledge ManagementPada Perusahaan Reasuransi: Studi Kasus PT Reasuransi Nasional Indonesia. http://riyogarta.com/downloads/thesis_y uliazmi.pdf.

\section{Referensi}

Davidson, C., \& Voss, P. (2002). Knowledge management: An 